Journal of Education and Educational Development

8(1), 09-26, 2021

DOI: http://dx.doi.org/10.22555/joeed.v8i1.183

\title{
Covid-19 Pandemic and Possible Trends for the Future of Higher Education: A Review
}

\author{
Augustine Kara \\ Maasai Mara University, Kenya
}

\begin{abstract}
COVID-19 pandemic resulted in the abrupt closure of higher education institutions globally. The pandemic disrupted teaching, research, and community service in higher education resulting in a loss in revenue streams and human resources. To mitigate disruption on the academic calendar, institutions leveraged Information Communication Technology (ICT) to deliver administrative services and emergency remote teaching. A new equilibrium of disrupted classes with undisrupted learning through virtual platforms emerged. Some amplified challenges in the new norm include unreliable internet connectivity, access to ICT infrastructure, and preparedness for online pedagogy. Other difficulties include online delivery of science, technology, mathematics, practicals, and quality assurance. Thus, inequalities have been magnified between learners, institutions, and countries in response to the COVID-19 pandemic. Through a desktop review, this paper explores possible influences of the pandemic on the future of higher education. The study ultimately contends progressive uptake of blended learning as the new frontier in higher education. Institutions require capacity building on online pedagogy, greater investment in ICT infrastructure, and a holistic e-learning quality assurance framework that infuses achievement of desired learning outcomes with Maslow's Hierarchy of needs. A paradigm shift is expected towards the entrepreneurial university, institutional mergers, and strategic planning that incorporates disaster management.
\end{abstract}

Keywords: Covid-19, higher education, ICT in education.

\section{Introduction}

In December 2019, the world was ushered to a baffling phenomenon that escalated into a global crisis in the form of COVID-19 disease caused by a 
coronavirus. COVID-19 disease is characterized by fever, cough, fatigue, shortness of breath, pneumonia, and acute respiratory distress syndrome which in some cases, has resulted in death (WHO, 2020). The virus spreads rapidly from one person to another through respiratory droplets produced during talking, coughing, and sneezing (Cirrincione et al., 2020). Progressively, the virus spread across nations, and on 11th March 2020, the World health organization (WHO) declared COVID-19 a public health emergency of international concern (Gennaro et al., 2020). Currently, the COVID-19 virus has no specific antiviral treatment and prevention has largely been applied as the best practice to manage its spread (Khadka et al., 2020; Gennaro et al., 2020).

As part of a global response to prevent the spread of the COVID-19 virus, governments made urgent nationwide decrees and decisions affecting all sectors of the economy. Public health experts and government officials took measures which included enforced social distancing, self-isolation, quarantine, strengthening health facilities to control the disease, asking people to work from home, wearing masks in public places, temporal closure of places of worship and educational institutions (Gennaro et al., 2020; The World Bank, 2020). Closure of educational institutions, including higher education institutions, was premised on the fact that large gatherings of persons constitute a serious risk to public health during the pandemic (UNESCO, 2020a). Globally, almost all universities postponed oncampus events and activities to protect staff and students from COVID-19 virus infection (The World Bank, 2020). The temporal closure has extensively impacted the core functions of universities which include teaching, research, and community service (UNESCO, 2020a).

Higher education institutions were expected to devise strategies to mitigate the disruptive effects of the COVID-19 pandemic on their functions and operations for them to remain relevant. Furthermore, universities are regarded as intellectually advanced institutions to provide solutions for managing disruptions such as the current pandemic that has overwhelmed and stifled the economy (Crawford et al., 2020). As higher education institutions circumnavigate the catastrophic COVID-19 pandemic, impacts, mitigation measures, emerging challenges, and opportunities for transformation of higher education are to some extent documented (UNESCO, 2020b; Zhu \& Liu, 2020). This paper initiates discourse that may contribute to better outcomes in higher education by delving into the following objectives: 
1. Outline mitigation measures adopted by higher education institutions in the context of the COVID-19 pandemic.

2. Analysis of emerging challenges from the measures adopted to mitigate the impacts of the COVID-19 pandemic by higher education institutions.

3. Exploration of possible trends into the future of higher education in the context of the COVID-19 pandemic.

\section{Literature Review}

The temporal cessation of on-campus activities to mitigate the spread of the COVID-19 pandemic continues to register an enormous impact on higher education which is also segmented and differentiated within countries, across borders, and institutions (Altbach \& de Wit, 2020). UNESCO (2020a) acknowledges that in the absence of contingency plans for the immediate shift to remote learning, higher education institutions resulted in ad hoc closure which disrupted their academic calendars. Face-to-face classes, continuous assessment tests, and end of semester examinations were canceled. Graduations for final year students and preparations for the commencement of the new academic year have been postponed indefinitely to the detriment of the welfare of millions of students who invest in higher education with expectations of timely completion and entry into the job market (Dhawan, 2020; Jappie, 2020).

Mass displacement of students resulting in inaccessibility of vital campus services has also characterized the COVID-19 pandemic period where the international students found themselves in a devastating pandemic which they had neither predicted and nor were they prepared for. Some countries managed to repatriate their students while in some cases, individual students made their travel arrangements. To ensure the safety and well-being of students who could not travel due to restrictions imposed by the pandemic, some higher education institutions incurred high costs of hosting them (Marinoni \& van't Land, 2020). Although international students accommodated by host universities may have found themselves in deserted, lonely campuses and incurred costs that they had not planned for, students with accommodation outside the universities were worst affected. Sahu (2020) contends that it has been a great challenge for administrators to ensure food, accommodation, and safety for international non-resident students. 
The closure of higher education institutions has also impacted research engagements. Postgraduate students who were in the field collecting data could not complete their dissertations on time and even upon completion, there are uncertainties on opportunities for the presentation of research papers at conferences (Jappie, 2020). Due to social distancing and travel restrictions, it has been difficult for faculty to collaborate in research activities locally and internationally thus affecting the completion of field research projects and laboratory work (Marinoni $\&$ van't Land, 2020). Wigginton et al. (2020) report that on-site research activities have been disrupted in Australia, United States, Europe, and China. Researchers also have to contend with diminishing research funding which is likely to escalate as nations recover from the economic impacts of the COVID-19 pandemic. This will be more pronounced in developing countries that heavily depend on funding from European countries, United States, and lately, China (Mohamedbhai, 2020).

COVID-19 pandemic has impacted the financial health of higher education institutions. The most immediate financial impact is the loss of revenue from tuition fees and research due to closure (Soon, 2020). The pandemic comes at a time when higher education funding has already been declining and governments have reduced funding on higher education amid growing budget challenges (Blankenberger \& Williams, 2020). As the crisis persists, higher education in developing countries may experience a severe reduction in government funding as resources are channeled to other sectors expected to play a critical role in economic recovery (Altbach \& de Wit, 2020). Further, global support to higher education, research collaborations, and partnership schemes, most often directed at critical areas such as strengthening Ph.D. programs, could massively diminish (UNESCO, 2020a; World Bank, 2020). The sector has also lost its human resources as a result of COVID-19 disease-related deaths (Ogunode et al., 2020). Thus, Altbach and de Wit (2020) underscores that the COVID-19 pandemic will continue ravaging higher education and the impacts will be manifested with gaps and inequalities between learners, institutions, and countries with those in the poorest parts of the world being the worst affected. However, catastrophic including events such as the COVID-19 pandemic are change agents when introduced into an ecological system. It is therefore expected that higher education institutions will react to achieve a new equilibrium albeit with varied pace due to inextricably interwoven forces driving the system (Blankenberger \& Williams, 2020). 


\section{Methodology}

To conduct this study, secondary sources of data were used. Since the study has a global dimension, the review focused on available literature on the COVID-19 pandemic and higher education in Europe, North America, South America, Asia, Australia, and Africa. COVID-19 had not been reported in Antarctica and it was therefore not factored in the study. The review particularly focused on open access peer-reviewed journal articles published in the year 2020 during the COVID-19 pandemic. To develop thematic areas of interest in the study, literature not more than five years old was also reviewed. Also, e-contents, authentic websites, and various online reports from national and international agencies related to the COVID-19 pandemic and higher education institutions were analyzed. Data and information generated from the review were analyzed qualitatively guided by the thematic areas of study. The focus areas included background information on the COVID-19 pandemic, impacts of the pandemic on higher education, measures adopted to mitigate the effects of the COVID-19 pandemic in higher education, emerging challenges, and opportunities for transformation in higher education.

\section{Findings and Discussion}

\section{Mitigation Measures Adopted by Higher Education Institutions}

A salient response has been a rapid increase in the use of Information Communication Technology (ICT) to minimize disruptions in administrative operations and the delivery of academic programs through virtual platforms (Crawford et al., 2020). Since the emergence of COVID-19 disease, higher education institutions have adopted virtual administrative and governance mechanisms without affecting the quality of decisions made (UNESCO, 2020a). Most of the universities swiftly shifted to remote teaching as the only possible solution to mitigate disruptions of the academic calendar. The clarion call has been, "Disrupted classes, undisrupted learning" which was a contingency plan implemented by the Ministry of Education in China (Zhu \& Liu, 2020). Ali (2020), in a review of higher education response to the COVID-19 pandemic, observes that in Europe, universities are setting up technical systems needed to move courses, examinations, research, and administrative activities online. In Australia, higher learning institutions rapidly implemented online learning which has been supported by faculty familiarity with online teaching platforms and teaching approaches. In Italy, some universities distributed free SIM cards to enable continuing students to 
access the internet for purposes of online learning.

In India, Jena (2020) observes that the Ministry of Human Resource Development and University Grants Commission launched a variety of virtual platforms with online repositories, e-books, and other online teaching/learning materials for students to continue their learning during the COVID-19 pandemic period. Universities also started conducting orientation programs and counseling classes using different e-conferencing. In Pakistan, both faculty and students were using virtual platforms for purposes of teaching and learning (Mukhtaret et al., 2020). Johnson et al. (2020) observe that with a few exceptions, most of the universities in the United States of America (USA) have transitioned to emergency remote teaching regardless of prior experience with the new mode of delivery. Heitz et al. (2020) also report that some universities in the USA have been offering stipends for internet access and laptop rentals and purchases. This is aimed at ensuring that students access the necessary infrastructure at a favorable cost. Universities have also increased partnerships with online providers of mental health services to support students manage the anxiety and distress caused by the COVID-19 pandemic.

In Colombia and Paraguay where prior accreditation is required before offering distance education, higher education institutions were immediately authorized to shift to remote teaching (UNESCO, 2020a). In China, the Ministry of Education guided the organization and management of online emergency programs in higher education institutions during the epidemic prevention and control period. National and local governments were required to encourage and support colleges, universities, and society in the joint implementation of online learning. The Ministry of Education demanded that online courses should be of the same quality as face-to-face courses. Teachers' online courses workload was to be recognized as equivalent to teacher workload in delivering face-to-face courses. The framework also encourages students towards online self-directed learning. Universities were urged to conduct multi-dimensional learning evaluations and to appropriately credit students' online achievements (Zhu \& Liu, 2020).

In Africa, Tamrat and Teferra (2020) indicate that in countries such as Rwanda, South Africa, and Tunisia, universities are partnering with internet providers and governments to negotiate zero-rated access to specific educational 
and information websites. Some universities are also offering data bundles to their students and staff to facilitate online learning. Adeoye et al. (2020) observe that, unlike public universities, private universities in Nigeria embraced online learning to ensure that their academic calendar was not distorted. In Kenya, the State Department for University Education and Research instructed universities to ensure virtual orientation for newly admitted students. Universities were also encouraged to hold virtual graduations for students who had completed their academic programs and met graduation requirements as set by their respective Senates. Further, they were expected to promote remote learning to mitigate the effects of the COVID-19 pandemic on institutional academic calendars. Universities were also mandated to form technical committees to plan and implement guidelines and protocols on COVID-19 pandemic mitigation (MOE, 2020).

\section{Emerging Challenges in Response to COVID-19 in Higher Education Institutions}

Access to online learning infrastructure and reliable internet connectivity, even where the universities have availed data bundles to students and staff, has been cited as a recurring constraint (The World Bank, 2020; Zhong, 2020). Dill et al. (2020) observe that in U.SA, internet access is a challenge especially for students and faculty in small cities and towns. Internet services slow down when demand is high such as when there is a high volume of videoconferencing. Zhu and Liu (2020) concede that poor internet access has been a key challenge in the 'Disrupted classes, undisrupted learning' contingency plan in China. Marinoni and van't Land (2020) reveal that in Brazil, internet access for students is so limited that some universities completely abandoned remote teaching. Hence poor internet connectivity is a global issue and is one of the main reasons for disruptive learning.

\section{Equity in Access to Remote Teaching}

Concerns have been raised that remote teaching is excluding socially and economically disadvantaged students. The rapid transition to remote teaching during the COVID-19 pandemic assumed that all students have a favorable home environment for study. However, some students live in overcrowded homes with amenities inadequate for learning; this is likely to perpetuate huge inequalities and disparities in learning opportunities and outcomes (Dhawan, 2020; Jappie, 2020b; Zhong, 2020). A study conducted by Kapasiaa et al. (2020) in universities in West Bengal state in India found that during the COVID-19 pandemic, students 
from remote and marginalized areas are facing enormous challenges with internet connectivity and unfavorable study environment at home. Mohmmed et al. (2020) also contend that lecturers are distracted by domestic chores and parenting which may have a dissenting impact on remote teaching.

\section{Readiness for Emergency Online Teaching and Learning}

Concerns have been raised on pedagogical, digital literacy, and attitude to support the massive implementation of online learning. Dill et al. (2020) emphasize that many university lecturers have never taught online and there was no time to provide meaningful training. Mohamedbhai (2020) argues that at present, lecturers are merely posting their notes online since they lack pedagogical skills for online teaching. The current provision can hardly pass the test of online pedagogy. Some faculty, due to inexperience with online teaching and pride in a brick-and-mortar learning experience on campus, believe that online teaching is inferior to the face-to-face mode of delivery. Such attitudes create chaos and uncertainty in the institutional response to the COVID-19 pandemic (Ali, 2020; Hong, 2020). Nenko et al. (2020) study on online learning in Ukrainian higher educational institutions during the COVID-19 pandemic found that faculty unpreparedness for online education, negative attitude, low motivation to develop online teaching content, and adoption of remote technologies were some of the challenges affecting the implementation of online instruction.

Due to COVID-19 pandemic restrictions, students require the capacity for self-disciplined and self-directed active learning. They require skills to learn, communicate, seek guidance, attain the ability to converse and interact with their peers and instructors during virtual interactions. Students should be adaptive to the assessment strategy that will be applied in online classes (Mohmmed et al., 2020). The ad hoc nature of implementation of remote teaching immersed students in platforms devoid of socialization components experienced in face-to-face classes and with inadequate skills for meaningful virtual learning. A study in Pakistan found that university students expressed dissatisfaction with emergency online learning due to lack of access to reliable internet services, limited learner-instructor interaction, and absence of traditional classroom socialization (Adnan \& Anwar, 2020). Confronted with these limitations, the majority $(50.8 \%)$ of the students were uncertain of effectively completing their programs through online learning. 


\section{Assessment of Learning in Remote Teaching}

Most of the teachers and students transited to online learning without any competencies and experience in conducting online assessments; consequently, students could not receive immediate feedback on the progress of learning (Mukhtar, et al., 2020). Although students may be issued with take-away assignments, many higher education institutions do not have existing policies to allow for virtual assessment of learners (ADEA, 2020; Jappie, 2020). After months of delivering online instruction during the COVID-19 pandemic, many institutions are currently struggling with how to offer end-of-semester examinations online while achieving the desired objectives and assuring quality.

\section{Resource Constraints}

Financial resources are require in setting up an online learning infrastructure, maintaining equipment, training human resources, and developing online content. Both the students and faculty may not have the financial resources to sustain online learning without intervention from the institutions which are already financially constrained (Zhong, 2020; Zhu \& Liu, 2020).

\section{Delivery of Field and Practical Courses}

Science, Technology, Mathematics, and field courses have generally presented more difficulties in the virtual adaptation process especially with the lack of online pedagogy among instructors and learners (UNESCO, 2020a). Due to restricted movements as a result of the COVID-19 pandemic, students cannot access laboratories in their universities for practical work. They cannot be attached to the industry for practical learning experiences (Mohamedbhai, 2020). Mukhtar et al. (2020) study conducted in Pakistan found that students and lecturers were unable to teach and learn practical and clinical work. They could only teach and assess the knowledge component. This predicament is aptly captured by Jappie (2020) who poses a series of questions that provoke reflection. Can the teaching practice component of education students be conducted and assessed online? Can such students learn how to handle a class with only virtual training? Can agricultural and veterinary students acquire the necessary skills to conduct complex protocols in the industry if they have only received online instruction? And could a student qualify for a job when virtual/online training is not the only aspect required? These questions need thoughtful consideration by academia to effectively engage in 
teaching and learning in practical fields.

\section{Quality Assurance in Online Learning}

Apart from institutions that had accredited online learning programs, most of the institutions transited to online learning without any accreditation. Consequently, emergency remote teaching has been characterized by a lack of standards for quality assurance and control in the development of online learning resources, virtual learning environment, communication, cooperation and interactivity, students' assessment, flexibility and adaptability, support for both staff and students, vision and institutional leadership and resource allocation among other parameters for quality assurance in online programs (Dhawan, 2020; Zhu \& Liu, 2020). Amemado (2020) contextualizes the emerging challenges in transitioning to online education during the COVID-19 pandemic globally. He observes that for African universities, institutions are constrained by connectivity issues, lack of infrastructure, and cost of data bundles. In Asian countries, institutions have to grapple with financial costs, regulations, the digital gap, and the cultural leap for teachers. In Europe, the challenge has been students' self-motivation and self-organization skills in fully online educational settings. In North American and Australian universities, institutions have to confront rapid technological changes and acculturing faculty to changes. In Latin America, the obstacles are achieving a higher level of engagement among students and ensuring course quality. Though he acknowledges that the analysis is not comprehensive, it nevertheless demonstrates that there is not a single content that is devoid of challenges in the wake of the rapid and ad-hock transition to online education during the COVID-19 pandemic.

\section{Possible Trends into the Future of Higher Education in the Context of COVID-19}

It is important to emphasize that the COVID-19 virus is a reality that we have to live with for some time. As such, it may not be possible for higher education institutions to revert to normal operations especially with the fear of new and recurring infections. This paper has demonstrated that emergency remote teaching has limitations in terms of quality, access, and equity; therefore, it would be overly ambitious to envision a future of purely online provision of higher education. The World Bank (2020) cautions that a large-scale shift to online learning is a complex undertaking for education systems, even in the best of circumstances. However, as demonstrated by measures adopted to mitigate the impacts of the COVID-19 
pandemic, higher education institutions are cognizant of the rapid growth and potential of ICT on the education sector, its influence in almost all spheres of life, and the need for functional ICT literacy in nearly all life engagements. The fact that the modern student has a high affinity for technology and desires technologyenhanced learning cannot be ignored (Ali, 2020).

Moving into the future, a combination of face-to-face and online learning may be the new norm. In an academic program, theoretical components may be offered online even when students are on-campus. As universities learn from their experiences and best practices elsewhere, technology may be deliberately, progressively, and extensively infused into delivering practical subjects including sciences, technology, and mathematics. Higher education institutions must therefore be persuaded to embrace bimodal delivery of academic programs and make access to online education more affordable, convenient, and engaging to learners from all walks of life (Amemado, 2020). This paradigm shift will demonstrate the commitment of higher education institutions in leveraging technology to facilitate flexible, adaptive learning environments and empowering the youth with handson digital literacy which is a key ingredient in the actualization of sustainable development goals (Dhawan, 2020).

\section{Investment in ICT Infrastructure and Personnel}

COVID-19 pandemic has demonstrated that magnificent physical infrastructure on campus, though an essential part of a quality learning environment, can be superfluous; consequently, universities must invest more in ICT infrastructure, personnel to provide the much-needed technological support, and empower their human resources on technology adoption and use. Partnership and collaboration with government and key stakeholders in the ICT sector will be essential in mitigating the digital divide that is occasioned by high costs of ICT hardware and software, rural-urban divide in access to reliable internet, costs, among other factors.

\section{ICT Literacy and Online Pedagogy}

In the past, higher education institutions have focused more on the faculty's knowledge in the subjects of specialization whose indicators are academic certificates, research publications, and related community service. The paradigm shift to blended learning demands ICT literacy and online pedagogy among faculty 
as a core competence for new entrants into the academia and sustained in-service professional development programs for existing faculty. During the COVID-19 pandemic, various virtual initiatives managed by international associations in higher education have been empowering individual lecturers to transition to online teaching and learning. For instance, the European Universities Association (EUA), International Association of Universities (IAU), the Inter-American Organization for Higher Education (IOHE), the Association of African Universities (AAU), and Teacher Education in Sub-Saharan Africa (TESSA) have been offering a series of free webinars on online teaching and learning to voluntary participants during the COVID-19 pandemic. Although this is commendable, such initiatives should be identified, supported and institutional partnerships entrenched to ensure that no faculty is left behind in bridging the online pedagogy divide. Universities must demonstrate deliberate and conscious efforts to bring all students on board in pursuit of online learning. There is a need for structured online pedagogy programs during induction of the first year and ongoing students to empower them to productively use technology for learning. As Ali (2020) points out, the modern university student may be technology canny but may lack the theoretical and practical knowledge base required for online pedagogy.

\section{Quality Assurance in Online Teaching and Learning}

Currently, higher education service is extensively commercialized. Students desire and seek a superior quality educational service experience both locally and internationally. Institutions offering the desired campus experience have been the biggest beneficiaries leading to a competitive higher education market. As we move into the post-COVID-19 pandemic period, the new battlefront is likely to shift to the quality of blended learning and outcomes. Consequently, universities that will embrace total quality management practices in bimodal mode and present a superior quality experience will secure and sustain admissions. During the pandemic, there are concerns that faculty and learners' emotional needs are not being adequately addressed hence loss of sense of a community. Consequently, universities should pursue a holistic quality assurance framework that not only assures achievement of desired learning outcomes but also the psychosocial needs of students. Universities will be expected to demonstrate a fair fusion of Maslow's hierarchy of needs with Bloom's taxonomy for them to remain relevant and competitive (Flack et al., 2020; Zhu \& Liu, 2020). 


\section{Greater Emphasis of the Entrepreneurial University}

Higher education institutions should brace for reduced government capitation as priority is accorded to service sectors that will support the recovery of battered economies. A decline in revenue in the form of students' fees and donor-funded research is a reality that the institutions will contend with. Transformation towards the entrepreneurial university will be inevitable with non-responsive universities eventually exiting the market. Though a contentious debate, the entrepreneurial university is characterized by the strategic alignment of the core competencies of teaching, research, and community service to the external environment and the needs of its stakeholders. Universities will therefore be expected to dedicate themselves to demonstrating the value of their services through an open and flexible process of open engagement, symbiotic learning, discovery, and exchange of ideas with local, national, and international partners in the society (Jameson \& O’Donnell, 2015).

Transitioning to the entrepreneurial university is not an event. It is a deliberate, conscious, systematic, and rational evolution to profit-making institutions through strategic community engagement. In the context of COVID-19 pandemic recovery, higher education institutions will be required to demonstrate desirable economic and social impact at local, regional, and national levels. This will only be achieved by universities recognizing, adopting, and promoting entrepreneurial actions, orientation, education, structures, practices, culture, and research across the entire system (Pugha et al., 2018). As Altbach and de Wit (2020) point out, the post-COVID-19 period will provide impetuous to university - society orientation. In particular, institutions that will help societies manage and resolve the impacts of the pandemic will receive greater emphasis and funding. Teter and Wang (2020) submit that some universities will have the available capacity to effectively meet university-society-industry needs. However, the majority of higher education institutions must reassess their place-based relevance, given the COVID-19 pandemic and its impacts on society.

\section{Institutional Mergers}

Confronted with serious financial risks and the need for entrepreneurial universities, mergers will be inevitable. Governments must strategically analyze the strategic future of higher education institutions and identify threats and opportunities which will be best addressed through institutional mergers in a post- 
COVID-19 pandemic. It makes no economic sense to have numerous public and private higher education institutions with an almost similar mission and vision competing for scarce resources within the same environment. Moving into the future, public-public and public-private higher education institutions mergers and consolidation will be inevitable as a strategic option towards achieving economies of scale, improving organizational methods leading to more effective market operation and fulfillment of their mission and vision (Anichkin, 2018).

\section{Institutionalizing Contingency Planning}

This paper has demonstrated that in the absence of contingency planning, even the best-rated higher learning institutions are overwhelmed by the COVID-19 pandemic. The spontaneous response purely for institutional survival has in most cases resulted in the chaos that threatens institutional core values. Moving into the future, higher learning institutions must outgrow from situational to proactive, strategic, and innovative responses to disasters and emergencies which are part of the organizational experience (Duraku \& Hoxha, 2020). Consequently, institutions must entrench contingency planning on disasters to prevent, prepare for, mitigate, respond to and recover from such eventualities and reduce the operational chaos and psychological impacts of disasters on students, staff, and other stakeholders.

\section{Conclusion and Recommendations}

Collectively, the impacts, mitigation measures, and emerging challenges in higher education institutions and systems in the context of the COVID-19 pandemic have been momentous. Globally, most higher learning institutions have demonstrated agility and resilience in response to the COVID-19 pandemic. Leveraging and scaling up the adoption of ICT to mitigate total disruption of institutional operations and core functions will certainly change the landscape of higher education. Building on their experiences with the implementation of large-scale emergency remote teaching during the COVID-19 pandemic period to generate evidence for efficacy and gaps to be addressed, higher education institutions should strategically shift to blended delivery of academic programs. More attention to the future of online provision of science, technology, and mathematics is required. Policymakers and practitioners in higher education must pay attention to a holistic quality assurance framework for a technology-supported educational experience that not only assures that desired learning outcomes are achieved but addresses socio-emotional needs, 
builds a sense of community, and pursues access and equity. There is a need to assure a balanced fusion of physical and virtual interaction to foster intellectual community and learning. Higher education institutions should strategically invest in ICT infrastructure and empower both faculty and students to harness the promise of technology to facilitate learning and skills development. Governments should consider offering a stimulus package to higher education institutions to develop their capacity for an ICT-supported operational environment.

Higher education institutions must, as a matter of priority, reflect on their modus operandi. Over-dependence on funding from the exchequer is no longer sustainable. As such, they should strategically align their core competencies of teaching, research, and community service to the external environment and the needs of their stakeholders. Through strategic community engagement, higher education institutions should fill the financing gap by generating additional revenue through symbiotic relationships in knowledge, technology transfer, and resource exchange activities. Cognizant of the high likelihood of resource constraints that will disrupt the higher education market, this paper posits that policymakers and practitioners should consider institutional mergers as a proactive strategy in pursuing sustainable growth, greater efficiency, economies of scale, improved value, and competitiveness. Although higher learning institutions have impressively managed the crisis in very difficult circumstances, they must pursue effective strategic planning to strengthen their responsiveness to disasters.

\section{References}

Adeoye, I. A., Adanikin, A. F. \& Adanikin, A. (2020). COVID-19 and E-Learning: Nigeria tertiary education system experience. International Journal of Research and Innovation in Applied Science, 5(5), 28 - 31.

Ali, W. (2020). Online and remote learning in higher education institutes: A necessity in light of COVID-19 Pandemic. Higher Education Studies, 10(3), 16 - 25.

Altbach, P. G. \& de Wit, H. (2020). Post-pandemic outlook for higher education is bleakest for the poorest. International Higher Education, 102, 3 - 5.

Amemado, D. (2020). COVID-19: An unexpected and unusual driver to online education. International Higher Education, 102, 12 - 14.

Arnhold, N., Brajkovic, L., Nikolaev, D. \& Zavalina, P. (2020). Tertiary Education and COVID-19: Impact and Mitigation Strategies in Europe and Central Asia. file://C:/ Users/user/Downloads/ECATEandCOVID19longFINAL25May20.pdf 
Blankenberger, B. \& Williams, A. M. (2020). COVID and the impact on higher education: The essential role of integrity and accountability. Administrative Theory \& Praxis, 42(3), 404-423. https://doi.org/10.1080/10841806.2020.1771907

Cirrincione, L., Plescia, F., Ledda, C., Rapisarda, V., Martorana, D., Moldovan, R. E., Theodoridou, K., \& Cannizzaro, E. (2020). COVID-19 andemic: Prevention and protection measures to be adopted at the workplace. Sustainability, 12(9). https:// doi.org/10.3390/SU12093603

Crawford, J., Butler-Henderson, K., Rudolph, J., Malkawi, B., Glowatz, M., Burton, R., Magni, P. A., \& Lam, S. (2020). COVID-19: 20 countries' higher education intraperiod digital pedagogy responses. Journal of Applied Learning \& Teaching, 3(1), 1-20. https://doi.org/10.37074/jalt.2020.3.1.7

Dhawan, S. (2020). Online learning: A panacea in the time of COVID-19 Crisis. Journal of Educational Technology Systems, 49(1), 5-22.

Dill, E., Fischer, K., Mcmurtrie, B. \& Supiano, B. (2020). As coronavirus spreads, moving classes online is the first step. What's next? The Chronicle of Higher Education. https://www.chronicle.com/article/as-coronavirus-spreads-the-decision-to-moveclasses-online-is-the-first-step-what-comes-next/

Flack, C. B., Walker, L., Bickerstaff, A., Earle, H., \& Margetts, C. (2020). Educator perspectives on the impact of COVID-19 on teaching and learning in Australia and New Zealand. Pivot Professional Learning.

Di Gennaro, F., Pizzol, D., Marotta, C., Antunes, M., Racalbuto, V., Veronese, N., \& Smith, L. (2020). Coronavirus diseases (COVID-19) current status and future perspectives: A narrative review. International Journal of Environmental Research and Public Health, 17(8), 2690.

Heitz, C., Laboissiere, M., Sanghvi, S. \& Sarakatsannis, J. (2020). Getting the next phase of remote learning right in higher education. https:/www.mckinsey. com/ /media/McKinsey/Industries/Public\%20and\%20Social\%20Sector/ Our\%20Insights/Getting\%20the $\% 20$ next $\% 20$ phase $\% 20$ of $\% 20$ remote $\% 20$ learning\%20right $\% 20 \mathrm{in} \% 20$ higher $\% 20$ education/Getting-the-next-phaseof-remote-learning-right-in-higher-education.pdf

Hong, B. (2020). COVID-19 pandemic and South Korean higher education: A threat with a silver lining? International Higher Education, 102, 26 -27.

Jameson, J. \& O'Donnell, P. (2015). The entrepreneurial university: A unifying theme for TU4Dublin? Stream 1: Enterprise and Engagement, 6. https:// arrow.tudublin.ie/st1/6

Jappie, N. (2020). Governance and management- higher education response to 
COVID-19. file:///C:/Users/user/Downloads/Theme\%208_Governance\%20 $\& \% 20$ Management $\% 20$ in $\% 20$ Higher $\% 20$ Education $\% 2014 \% 2005 \% 20$ FINAL\%20(4).pdf

Jena, P. K. (2020). Impact of Covid-19 on higher education in India. International Journal of Advanced Education and Research, 5(3), 77 - 81.

Johnson, N., Veletsianos, G., \& Seaman, J. (2020). U.S. faculty and administrators' experiences and approaches in the early weeks of the COVID-19 pandemic. Online Learning, 24(2), 6-21. https://doi.org/10.24059/olj.v24i2.2285

Kapasia, N., Paul, P., Roy, A., Saha, J., Zaveri, A., \& Mallick, R. (2020). Children and youth services review impact of lockdown on learning status of undergraduate and postgraduate students during covid-19 pandemic in West Bengal, India. Children and Youth Services Review, 116.

Khadka, S., Hashmi, F. K., \& Usman, M. (2020). Preventing COVID-19 in low-and middle-income countries. Drugs \& Therapy Perspectives, 36(6), 250-252.

Marinoni, G. \& van't Land, H. (2020). The impact of COVID-19 on global higher education. International Higher Education, 102, 7 - 9.

Mohamedbhai, G. (2020). COVID-19: What consequences for higher education in Africa? International Higher Education, 102, 30 - 32.

Mohmmed, A. O., Khidhir, B. A., Nazeer, A. \& Vijayan, V. J. (2020). Emergency remote teaching during Coronavirus pandemic: The current trend and future directive at Middle East College Oman. Innovative Infrastructure Solutions, 5(72), $1-11$.

Mukhtar, K., Javed, K., Arooj, M. \& Sethi, A. (2020) Advantages, limitations and recommendations for online learning during COVID-19. https://doi. org/10.12669/pjms.36.COVID19-S4.2785

Ogunode, O., Abigeal, I. \& Lydia, A. E. (2020). Impact of COVID-19 on the higher institutions development in Nigeria. Electronic Research Journal of Social Sciences and Humanities, 2(2), $126-135$.

Pugha, R., Lamine, W., Jack, S. \& Hamilton, E. (2018). The entrepreneurial university and the region: What role for entrepreneurship departments? European Planning Studies, 26(9), 1835-1855.

Sahu, P. (2020). Closure of universities due to Coronavirus Disease 2019 (COVID-19): Impact on education and mental health of students and academic staff. https:/www.ncbi.nlm.nih.gov/pmc/articles/PMC7198094/ pdf/cureus-0012-00000007541.pdf

Tamrat, W. \& Teferra, D. (2020). COVID-19 Threat to higher education: Africa's 
challenges, responses, and apprehensions. International Higher Education, 102, 28-30.

Teter, W. \& Wang, L. (2020). COVID-19 and UNESCO: Monitoring the impact on people and places for relevant higher education. https://headfoundation. org/HESB8/COVID-19-and-UNESCO

The World Bank, (2020). The COVID-19 Crisis Response: Supporting tertiary education for continuity, adaptation, and innovation. http://pubdocs. worldbank.org/en/621991586463915490/WB-Tertiary-Ed-and-Covid-19Crisis-for-public-use-April-9.pdf

UNESCO, (2020a). COVID-19 and higher education: Today and tomorrow; Impact analysis, policy responses and recommendations. http://pubdocs. worldbank.org/en/621991586463915490/WB-Tertiary-Ed-and-Covid-19Crisis-for-public-use-April-9.pdf

UNESCO (2020b). UNESCO COVID - 19 Education Response - Education Sector Issue Notes. https://reliefweb.int/sites/reliefweb.int/files/resources/75890. pdf

WHO (2020) Coronavirus disease (COVID-19) advice for the public. https://www. who.int/emergencies/diseases/novel-coronavirus-2019/advice-for-public.

Wigginton, N. S., Cunningham, R. M., Katz, R. H., Lidstrom, M. E., Moler, K. A., Wirtz, D., \& Zuber, M. T. (2020). Moving academic research forward during COVID-19. Science, 368(6496), 1190-1192.

$\mathrm{Wu}, \mathrm{Z}$. (2020). How a top Chinese university is responding to coronavirus. https://www. weforum.org/agenda/2020/03/coronavirus-china-the-challenges-of-onlinelearning-foruniversities/

Zhang, W., Wang, Y., Yang, L. \& Chuanyi, W. (2020). Suspending classes without stopping learning: China's education emergency management policy in the COVID-19 outbreak. Journal of Risk and Financial Management, 13(3), 55.

Zhong, R. (2020, March 17). The coronavirus exposes education's digital divide. The New York Times. https://www.nytimes.com/2020/03/17/technology/chinaschoolscoronavirus.html

Zhu, X., \& Liu, J. (2020). Education in and after Covid-19: Immediate responses and longterm visions. Postdigital Science and Education, 2(3), 695-699. 